\title{
Maspin expression in CIN 3, microinvasive squamous cell carcinoma, and invasive squamous cell carcinoma of the uterine cervix
}

\author{
Chengen Xu, M Ruhul Quddus, C James Sung, Margaret M Steinhoff, Cunxian Zhang \\ and W Dwayne Lawrence
}

Department of Pathology, Women and Infants Hospital and Brown Medical School, Providence, RI, USA

\begin{abstract}
Maspin is a serine protease inhibitor with tumor suppression activity. It is expressed in normal breast and prostate tissue but is downregulated or absent in breast and prostate tumors. Recent reports have shown that decreased expression is associated with a greater propensity for metastasis in oral squamous cell carcinomas. We know that some high-grade cervical intraepithelial neoplasia progress to invasive carcinomas while others either persist at the same degree of atypia or regress. The pattern of maspin expression in cervical intraepithelial neoplasia-grade 3, microinvasive squamous carcinomas and overtly invasive squamous cell carcinomas of the uterine cervix was studied to determine the relationship between the extent of maspin expression and the progression of cervical intraepithelial neoplasia to squamous cell carcinoma. In total, 36 cases were evaluated: 18 cases of cervical intraepithelial neoplasia-grade 3 , seven cases of microinvasive squamous cell carcinoma and 11 cases of invasive squamous cell carcinoma. A monoclonal antibody was used on paraffin-embedded tissues. Immunoreactivity was scored semiquantitatively using a scale of $0-3$. The sums of the scores of the different groups were compared using the Mann-Whitney U-test. A significant decrease in maspin scores was noted between cervical intraepithelial neoplasia-grade 3 vs invasive squamous cell carcinoma $(P<0.005)$, microinvasive squamous cell carcinoma vs invasive squamous cell carcinoma $(P<0.05)$, and cervical intraepithelial neoplasia-grade 3 vs tumor emboli $(P<0.005)$. Although not statistically significant, scores of cervical intraepithelial neoplasia-grade 3 associated with invasive squamous cell carcinoma were lower compared to that cervical intraepithelial neoplasia-grade 3 without invasive squamous cell carcinoma. These findings suggest that maspin likely plays a role in disease progression from in situ to invasive carcinoma. Virtual absence of maspin immunopositivity in tumor emboli indicates that maspin may also play a role in metastasis.

Modern Pathology (2005) 18, 1102-1106. doi:10.1038/modpathol.3800393; published online 25 February 2005
\end{abstract}

Keywords: cervix; CIN; maspin; squamous cell carcinoma

Maspin was identified as a tumor suppressor gene by subtractive hybridization from normal mammary epithelial cells. ${ }^{1}$ It is a member of the serine protease inhibitor serpin superfamily and is located at $18 \mathrm{q} 21.3$, along with other serpin genes such as squamous cell carcinoma antigens 1 and 2 and PAI$2{ }^{2}$ Accumulated evidence has demonstrated its role as a tumor suppressor that both inhibits cell motility and enhances the capacity for invasion and meta-

Correspondence: Dr MR Quddus, MD, Department of Pathology, Women and Infants Hospital, 101 Dudley Street, Providence, RI 02905-2499, USA.

E-mail: Mquddus@wihri.org

The results of this study were presented in part at the 92nd annual meeting of the United States and Canadian Academy of Pathology in Washington, DC, March 2003.

Received 4 August 2004; revised 10 January 2005; accepted 11 January 2005; published online 25 February 2005 stasis in breast cancer. ${ }^{3-8}$ In addition, maspin expression is downregulated in prostate carcinoma cell lines and is frequently absent in primary prostate cancers. ${ }^{8-13}$ Recent studies showed the regulation of maspin in response to androgen ablation of prostate cancer, which strongly implies that maspin plays a physiological role in growth inhibition ${ }^{9}$ and engenders a sensitizing effect on apoptosis. ${ }^{14}$ Oral squamous cell carcinomas that are immunopositive for maspin show a longer disease-free interval and overall survival period than tumors negative for maspin. Similarly, decreased maspin expression may significantly enhance the metastatic potential of stage I and II squamous cell carcinomas ${ }^{15,16}$ of the tongue. At present, the molecular and biological mechanisms of maspin functions are still unclear, although maspin was overexpressed in some tumors, including ovarian, pancreatic and gastric 
adenocarcinomas. ${ }^{17-20}$ The paradoxical expression of maspin in different types of tumors may provide new insights regarding the role of maspin in tumor progression, diagnosis and treatment strategies.

Cervical intraepithelial neoplasia (CIN) is very common in the uterine cervix. CIN represents preinvasive intraepithelial lesions that can either spontaneously regress to normal epithelium, persist at a certain degree of atypia, or progress to invasive cancer. In a relatively recent study, patients who were diagnosed cytologically and then followed cytologically and colposcopically (thereby eliminating the 'biopsy effect') confirmed the progression of preinvasive lesions to CIN 3 in $40-60 \%$ of patients. ${ }^{21}$ No studies have been performed to determine the expression of maspin in association with the regression or progression of CIN 3 of the uterine cervix. The aim of our study was to evaluate maspin expression in CIN 3, and microinvasive and invasive squamous cell carcinomas of the uterine cervix to determine if any relationship exists between maspin expression and the progression of CIN 3 to invasive squamous carcinoma.

\section{Materials and methods}

A total of 18 cases of CIN 3: seven cases of 'microinvasive' squamous cell carcinoma and 11 cases of invasive squamous cell carcinoma of the uterine cervix from the period 2001-2002, were retrieved from the archival files of the Department of Pathology, Women and Infants Hospital, Providence, RI. Microinvasive squamous carcinoma was defined according to the histologic criteria set forth by The Society of Gynecological Oncologists (SGO), namely 'one in which neoplastic epithelium invades the stroma in one or more places to a depth of $3 \mathrm{~mm}$ or less below the basement membrane of the epithelium and in which lymphatic or blood vascular involvement is not demonstrated. ${ }^{22}$ Formalin-fixed, paraffin-embedded tissue blocks were sectioned at 5- $\mu \mathrm{m}$ intervals, deparaffinized in ProPar clearant (Anatech Ltd, Battle Creek, MI, USA) twice for $10 \mathrm{~min}$, and hydrated gradually through graded alcohols $(100 \%$ ethanol twice and $95 \%$ ethanol twice). To enhance the immunostaining, an antigen retrieval procedure was performed. The deparaffinized sections were placed in a thermoresistant container filled with glycine-EDTA, $\mathrm{pH}$ 3.5, steamed for $15 \mathrm{~min}$, and then cooled for $20 \mathrm{~min}$ before immunostaining. The sections were sequentially incubated in $1.5 \%$ normal blocking serum in PBS, 1:500 dilutions of monoclonal maspin antibody (Santa Cruz, CA, USA), biotinylated secondary antibody, and avidin-biotinylated peroxidase. After a final wash with PBS, chromogenic detection and hematoxylin counterstain were performed.

Two pathologists (CX, MRQ) reviewed the slides independently to evaluate the maspin expression. Characteristic cytoplasmic granular staining is con-
Table 1 Scoring system of immunoreactivity

\begin{tabular}{|c|c|c|c|c|}
\hline & 0 & 1 & 2 & 3 \\
\hline Positive cells & $<10 \%$ & $10-25 \%$ & $26-50 \%$ & $>50 \%$ \\
\hline Intensity of staining & Negative & Weak & Moderate & Strong \\
\hline Staining uniformity & Negative & Scattered & Moderate & Uniform \\
\hline
\end{tabular}

sidered positive and the immunoreactivity was scored using a scale of $0-3$ based on the percentage of positive cells, intensity of staining and heterogeneity of staining (Table 1). When CIN 3 is noted adjacent to invasive squamous cell carcinoma, both the CIN 3 and invasive squamous cell carcinoma are scored separately. The sums of the scores from the different test groups were statistically compared using the Mann-Whitney $U$-test.

\section{Results}

Of the 18 cases of CIN 3, 15 exhibited moderate-tostrong maspin expression (immunoreactivity scores $\geq 5$ ) while three cases showed weak maspin expression (immunoreactivity scores: 3-4) (Figure 1a). Six of the seven microinvasive squamous cell carcinomas expressed moderate staining for maspin (immunoreactivity scores: 4-5) (Figure 1b), whereas one case strongly expressed maspin with an immunoreactive score of 7 . Eight of the 11 cases of invasive squamous cell carcinoma showed only weak maspin expression (immunoreactive scores $\leq 4$ ) (Figure 1c). Two cases of invasive squamous cell carcinoma had adjacent CIN 3. Maspin scores of the CIN 3 in these two cases were 4 in each case. Four cases of invasive squamous cell carcinoma exhibited vascular space invasion. Interestingly, maspin expression in the 'intravascular tumor emboli' was very weak to virtually negative (Figures 1d). The mean and median ages of the patients with invasive squamous cell carcinomas were almost 20 years older than those of the patients with CIN 3 and microinvasive squamous cell carcinomas (Table 2).

The Mann-Whitney $U$-test was performed to compare the maspin expression among CIN 3, microinvasive, and invasive squamous cell carcinomas of the uterine cervix. Maspin expression in CIN 3 and microinvasive squamous cell carcinoma was significantly stronger than that in invasive squamous cell carcinoma $(P<0.005, \quad<0.05$, respectively). However, maspin expression between CIN 3 and microinvasive squamous cell carcinoma was not significantly different. The low expression of maspin observed in intravascular tumor emboli is statistically significant when compared with CIN 3 and microinvasive squamous cell carcinoma $(P<0.005)$ (Table 3). There was no significant difference in maspin expression between invasive squamous cell carcinoma and intravascular tumor emboli. 

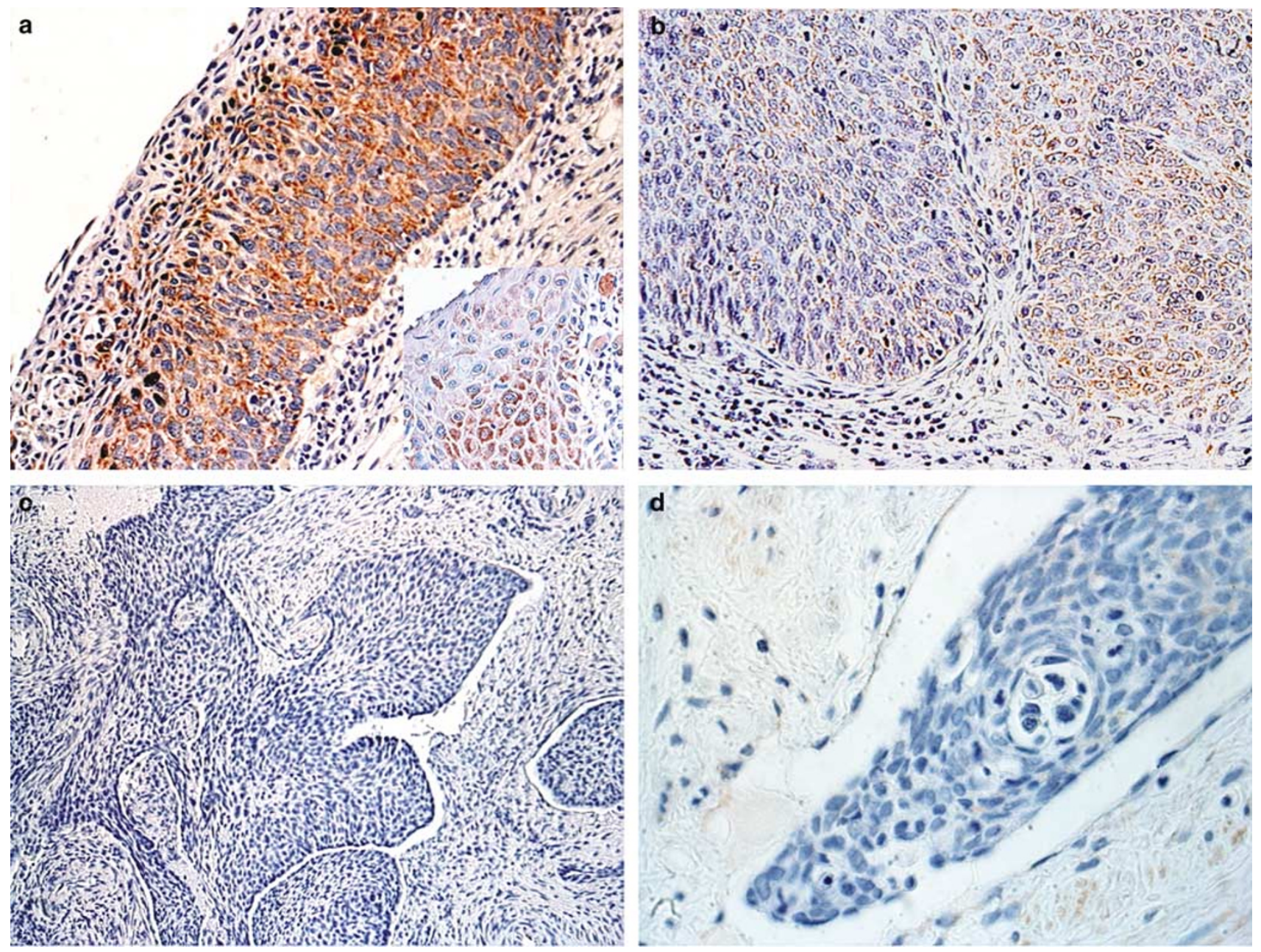

Figure 1 (a) Strong cytoplasmic granular maspin expression in CIN 3 of uterine cervix $(\times 200)$ and benign cervical squamous epithelium $(\times 200)$ (inset). (b) Focal weak to moderate cytoplasmic maspin expression in microinvasive squamous cell carcinoma of uterine cervix $(\times 200)$. (c) Very weak to negative cytoplasmic maspin expression in invasive squamous cell carcinoma of uterine cervix $(\times 100)$. (d) Absence of maspin expression in an intravascular tumor embolus $(\times 400)$.

Table 2 Range, mean and median age of different study groups

\begin{tabular}{lccc}
\hline Diagnosis & $\begin{array}{c}\text { Age range } \\
\text { (years) }\end{array}$ & $\begin{array}{c}\text { Mean age } \\
\text { (years) }\end{array}$ & $\begin{array}{c}\text { Median age } \\
\text { (years) }\end{array}$ \\
\hline CIN 3 & $20-77$ & 33.7 & 28.5 \\
Microinvasive & $19-46$ & 33.0 & 31.0 \\
SCC & $37-67$ & 51.2 & 51 \\
Invasive SCC & 37 & & \\
\hline
\end{tabular}

SCC, squamous cell carcinoma.

\section{Discussion}

Carcinoma of the uterine cervix was the leading cause of death from malignant disease in American women 50 years ago. Worldwide, cervical cancer is second only to breast cancer as the most common cancer in terms of both incidence and mortality rate. However, the mortality rate from cervical carcinoma has declined by more than half since the Papanico-
Table 3 Comparison of maspin expression in CIN 3, microinvasive squamous cell carcinoma and invasive squamous cell carcinoma of the uterine cervix

\begin{tabular}{lccc}
\hline $\begin{array}{l}\text { Immunoreactive } \\
\text { scores }\end{array}$ & $\begin{array}{c}\text { CIN 3 } \\
(\mathrm{n}=18)\end{array}$ & $\begin{array}{c}\text { Microinvasive } \\
\text { SCC }(\mathrm{n}=7)\end{array}$ & $\begin{array}{c}\text { Invasive } \\
\text { SCC }(\mathrm{n}=11)\end{array}$ \\
\hline Mean & 6.6 & 5.3 & 3.8 \\
Median & 7.0 & 5.0 & 3.0 \\
$P$-value & $<0.005$ (CIN 3 & $\begin{array}{c}<0.05 \\
\text { VS invasive) }\end{array}$ & $\begin{array}{c}\text { (Microinvasive } \\
\text { Vs invasive) }\end{array}$ \\
& & & \\
& &
\end{tabular}

SCC, squamous cell carcinoma.

laou smear was introduced for cytological screening in the 1940s. Yet despite the advances, cervical cancer is still the third most common malignancy of the female genital tract and the sixth most common solid cancer in women. Each year there are approximately 12800 new cases of invasive cervical 
carcinoma and more than 44000 new cases of CIN 3 in the United States, with the peak incidence for invasive carcinoma in women between the ages of 45 and 55 years. ${ }^{23,24}$ Cervical cancer causes an estimated 4800 deaths each year in the United States. Therefore, any tool that allows one to predict the potential for regression, progression, or even metastasis in patients with CIN 3 may be clinically relevant. A variety of factors, such as HPV testing for serotypes and subtypes, have been used to evaluate the potential for malignant transformation. HPV types $16,18,31,33,45$, and 56 are associated with malignant transformation and are frequently found in both squamous and glandular cervical cancers as well as their intraepithelial precursors. ${ }^{25}$

Maspin, a member of the serine protease inhibitors (serpins) super family, was originally identified in normal human breast epithelial and myoepithelial cell lines. ${ }^{1}$ Loss of maspin expression is found in some advanced tumors such as breast cancer and prostate cancers. ${ }^{3-5,10}$ However, overexpression of maspin is also seen in other tumors, for example, ovarian, pancreatic and gastric carcinomas. ${ }^{17-20}$ The paradoxical expression of maspin in different tumors is intriguing and most probably reflects the variation in pathogenesis of tumors of different organs of the body. It is interesting that maspin is not expressed in normal human pancreas and acquires its expression during tumorigenesis, ${ }^{26}$ similarly normal ovarian surface epithelial cells shows only low level of maspin expression. ${ }^{17}$ It is possible that the tissues that normally do not express maspin and express only low level of maspin, show an elevated maspin level during tumorigenesis.

Although the mechanism of its biological function is presently unclear, many studies have demonstrated that maspin is directly regulated by $p 53^{27}$ and inhibits tumor cell motility, invasion and metastasis $^{1,3-8,11}$ as well as tumor angiogenesis. ${ }^{28}$ These findings support the significance of maspin in the process of tumor progression. As in other neoplasms, the progression of CIN 3 to invasive cervical squamous cell carcinoma requires the attainment of certain properties that permit and enhance the capacity for tumor invasiveness and metastasis. Besides the kinetics of tumor cell growth and tumor angiogenesis, factors that alter extracellular matrix interactions are also essential for malignant potential. Maspin shares sequence homology with other inhibitory serpins such as plasminogen type-1 and -2 (PAI-1 and PAI-2). PAI-1 and $P A I-2$, inhibitors of urokinase-type plasminogen activator (uPA), work to decrease cell invasion by inhibiting the proteolytic degradation of extracellular matrix. uPA affects cell migration and spreading in vivo, as well as in vitro, through the activation of plasminogen and other protein factors at the cell surface or within the extracellular matrix. Sheng et al have demonstrated that maspin interacts with single-chain tissue plasminogen activator (sctPA), forming a stable complex that specifically inhibits sctPA. The latter suggests a mechanism by which maspin may regulate sctPA activity on the cell surface. $^{29}$ Indeed, a recent report found a direct interaction between exogenous (or cell surface) maspin and extracellular matrix collagen. ${ }^{30}$ Such findings suggest that maspin may also have a cell adhesion role to prevent tumor cell migration and angiogenesis.

In the present study, a significantly diminished level of maspin expression was observed between CIN 3 vs invasive squamous cell carcinoma $(P<0.005)$, microinvasive vs invasive squamous cell carcinoma $(P<0.05)$, and CIN 3 vs tumor emboli $(P<0.005)$. Diminished maspin expression is not identified between normal squamous epithelium and CIN 3 (Figure 1a). The level of maspin expression in microinvasive squamous cell carcinoma is lower than in CIN 3, but the difference is not statistically significant. However, there appears to be a trend that might achieve statistical significance if larger number cases are examined. Diminished maspin expression (median maspin score $=4$ ) is found in two cases of CIN 3 adjacent to invasive squamous cell carcinoma compared to cases of CIN 3 without invasive carcinoma (median maspin score $=7$ ). However, larger number of cases needs to be examined to confirm the finding. Maspin expression in tumor emboli within vessels was virtually absent. Our findings suggest that loss of maspin expression is not an early event in tumor transformation but rather, it plays a role in disease progression from CIN 3 to invasive squamous cervical carcinoma, and possibly even metastasis.

In conclusion, maspin may be a potentially useful marker to identify the potential for progression in cervical intraepithelial squamous lesions, since lower immunoreactivity scores are found in CIN 3 associated with invasive carcinoma as compared to CIN 3 without invasion. The virtual absence of maspin in tumor emboli of squamous carcinoma may support a role for maspin in metastasis.

\section{Duality of Interest}

None declared.

\section{References}

1 Zou Z, Anisowicz A, Hendrix MJ, et al. Maspin, a serpin with tumor-suppressing activity in human mammary epithelial cells. Science 1994;263:526-529.

2 Schneider SS, Schick C, Fish KE, et al. A serine proteinase inhibitor locus at $18 \mathrm{q} 21.3$ contains a tandem duplication of the human squamous cell carcinoma antigen gene. Proc Natl Acad Sci USA 1995;92:3147-3151.

3 Shi HY, Zhang W, Liang $\mathrm{R}$, et al. Blocking tumor growth, invasion, and metastasis by maspin in a 
syngeneic breast cancer model. Cancer Res 2001;61: 6945-6951.

4 Maass N, Hojo T, Rosel F, et al. Down regulation of the tumor suppressor gene maspin in breast carcinoma is associated with a higher risk of distant metastasis. Clin Biochem 2001;34:303-307.

5 Umekita Y, Ohi Y, Sagara Y, et al. Expression of maspin predicts poor prognosis in breast-cancer patients. Int J Cancer 2002;100:452-455.

6 Maass N, Hojo T, Zhang M, et al. Maspin-a novel protease inhibitor with tumor-suppressing activity in breast cancer. Acta Oncol 2000;39:931-934.

7 Maass N, Nagasaki K, Ziebart M, et al. Expression and regulation of tumor suppressor gene maspin in breast cancer. Clin Breast Cancer 2002;3:281-287.

8 Sheng S, Carey J, Seftor EA, et al. Maspin acts at the cell membrane to inhibit invasion and motility of mammary and prostatic cancer cells. Proc Natl Acad Sci USA 1996;93:11669-11674.

9 Abraham S, Zhang W, Greenberg N, et al. Maspin functions as tumor suppressor by increasing cell adhesion to extracellular matrix in prostate tumor cells. J Urol 2003;169:1157-1161.

10 Zou Z, Zhang W, Young D, et al. Maspin expression profile in human prostate cancer $(\mathrm{CaP})$ and in vitro induction of Maspin expression by androgen ablation. Clin Cancer Res 2002;8:1172-1177.

11 McGowen R, Biliran Jr H, Sager R, et al. The surface of prostate carcinoma DU145 cells mediates the inhibition of urokinase-type plasminogen activator by maspin. Cancer Res 2000;60:4771-4778.

12 Pierson CR, McGowen R, Grignon D, et al. Maspin is up-regulated in premalignant prostate epithelia. Prostate 2002;53:255-262.

13 Zhang M, Magit D, Sager R. Expression of maspin in prostate cells is regulated by a positive ets element and a negative hormonal responsive element site recognized by androgen receptor. Proc Natl Acad Sci USA 1997;94:5673-5678.

14 Jiang N, Meng Y, Zhang S, et al. Maspin sensitizes breast carcinoma cells to induced apoptosis. Oncogene 2002;21:4089-4098.

15 Yasumatsu R, Nakashima T, Hirakawa N, et al. Maspin expression in stage I and II oral tongue squamous cell carcinoma. Head Neck 2001;23:962-966.

16 Xia W, Lau YK, Hu MC, et al. High tumoral maspin expression is associated with improved survival of patients with oral squamous cell carcinoma. Oncogene 2000;19:2398-2403.
17 Sood AK, Fletcher MS, Gruman LM, et al. The paradoxical expression of maspin in ovarian carcinoma. Clin Cancer Res 2002;8:2924-2932.

18 Oh YL, Song SY, Ahn G. Expression of maspin in pancreatic neoplasms: application of maspin immunohistochemistry to the differential diagnosis. Appl Immuno-histochem Mol Morphol 2002;10: 62-66.

19 Maass N, Hojo T, Ueding M, et al. Expression of the tumor suppressor gene Maspin in human pancreatic cancers. Clin Cancer Res 2001;7:812-817.

20 Son HJ, Sohn TS, Song SY, et al. Maspin expression in human gastric adenocarcinoma. Pathol Int 2002;52: 508-513.

21 Meanwell CA. The epidemiology of human papillomavirus infection in relation to cervical cancer. Cancer Surv 1988;7:481-497.

22 Creasman WF, Fetter BF, Clarke-Pearson DL, et al. Management of stag IA carcinoma of the cervix. Am J Obstet Gynecol 1985;153:164-172.

23 Elkas JC, Farias-Eisner R, Berek JS. Cervix, vulva, and vagina. In: Abeloff MD, Armitage JO, Lichter AS (eds). Clinical Oncology, 2nd edn. Churchill Livingstone: New York, 2000, pp 1946-1966.

24 Sheets EE. The cervix. In: Ryan KJ, Berkowitz RS, Barbieri RL, Dunaif A (eds). Kistner's Gynecology \& Women's Health, 7th edn. Mosby Inc.: St Louis, MO, 1999, pp 93-120.

25 Lorincz AT, Reid R, Jensen V, et al. Human papillomavirus infection of the cervix: relative risk associations of 15 common anogenital types. Obstet Gynecol 1992;79:328-337.

26 Fitzgerald M, Oshario M, Holtan N, et al. Human pancreatic carcinoma cell activate maspin expression through loss of epigenetic control. Neoplasia 2003;5: 427-436.

27 Zou Z, Gao C, Nagaich AK, et al. p53 regulates the expression of the tumor suppressor gene maspin. J Biol Chem 2000;275:6051-6054.

28 Zhang M, Volpert O, Shi YH, et al. Maspin is an angiogenesis inhibitor. Nat Med 2000;6:196-199.

29 Sheng S, Truong B, Fredrickson D, et al. Tissue-type plasminogen activator is a target of the tumor suppressor gene maspin. Proc Natl Acad Sci USA 1998; 95:499-504.

30 Blacque OE, Worrall DM. Evidence for a direct interaction between the tumor suppressor serpin, maspin, and type I and III collagen. J Biol Chem 2002; 277:10783-10788. 